\title{
Photochemical production of gold films on the surface of fabric materials
}

\author{
Perizat Abdurazova, Malik Sataev, Gulmira Kenzhibayeva, Shayzada Koshkarbayeva, Kalamkas \\ Amanbayeva, Yerkebulan Raiymbekov*
}

\author{
M. Auezov South Kazakhstan State University, Shymkent, Republic of Kazakhstan \\ "Corresponding author: e-mail: eraiymbekov@gmail.com
}

\begin{abstract}
A technology for producing gold films on the surface of fabric materials has been developed, which provides for preliminary wetting of the fabric product with aqueous solutions of gold (III) chloride. In this case, a sorption layer of gold chloride is formed on the surface of fabric materials. Then, when drying these products under sunlight, physicochemical and photochemical processes occur, leading initially to the formation of monovalent gold chlorides, which, having semiconductor properties, provide the release of elemental gold. After washing of by-products on the surface of the material remains an ultra-thin film of gold, which has a sufficiently strong grip on the base. Since the proposed technology does not require special equipment it can be used to apply functional films of gold on various products of technical, household and medical purposes.
\end{abstract}

Keywords: gold, nanoparticle, antibacterial, fabric.

\section{INTRODUCTION}

Due to some features of physical and chemical properties, the coating of various materials made of gold has found wide applications in engineering, medicine and in everyday life. These features include: corrosion resistance, high electrical and thermal conductivity, low and stable transient resistance in time, catalytic activity, bactericidal, decorative appearance, ${ }^{1,2}$. The use of gold as a catalyst in the fuel system of cars is promising ${ }^{3}$. The exceptional ability of gold to reflect infrared rays allows it to be used in the glass industry, for the metallization of window panes of buildings. In the hot summer months, a significant amount of infrared radiation passes through the window panes of buildings, which leads to heating of the premises. If you use a special glass with an insert of a thin gold film (0.13 microns), it will reflect most of the infrared rays and lower the temperature in the building ${ }^{3}$.

The bactericidal activity of gold is lower than that of silver; however, a small addition of gold enhances the activity of silver. The combination of gold and silver nanoparticles can significantly extend the effect of silver used in the manufacture of antimicrobial clothing ${ }^{4}$.

There are a number of methods for coating or films on dielectric materials. These methods can be divided into physical and chemical. In the physical method, pre-molten metal particles are sprayed onto the coated surface with compressed air or gas. Liquid metal particles on the way to the surface are partially cooled and only melt the surface, sticking to it. A variation of this method is vacuum metallization ${ }^{5-7}$.

For the gilding of dielectrics, a method for depositing gold nanoparticles on silica microspheres is known, based on the thermal decomposition of volatile gold compounds. In this case, pairs of the volatile organometallic complex are used: dipivaloyl methanate dimethylgold, which at appropriate temperatures under vacuum conditions is reduced to form gold nanoparticles on the surface of microspheres ${ }^{8}$.

The advantage of physical methods of gilding is the possibility of applying gold directly to the surface of the product; the disadvantage is the need for expensive and complex installations. The disadvantage of a number of physical methods is also the need for preliminary preparation of metal nanoparticles, the difficulty of metallization of the internal surfaces of porous materials, the complexity of regulating the thickness of the coating.

For chemical deposition of metal coatings, reducing agents in the gas phase or compounds dissolved in an electrolyte solution are used.

Hydrogen ${ }^{9}$ and phosphine ${ }^{10}$ are proposed as reducing agents in the gas phase. The hydrogen reduction reaction is carried out at a high temperature, about several hundred degrees. In this way, it is possible to obtain coatings from a fairly large number of metals, but they need to have special equipment for heating and dosing of gas mixtures limits the wide application of the method. The use of phosphine allows the process to be carried out at low temperatures and to obtain coatings containing non-metallic inclusions, in a particular diamond. In addition, with this method, it is possible to obtain coatings that have a decorative effect. But in general, this method is associated with certain difficulties due to the toxicity of the gas and the need for the process in sealed devices.

As liquid-phase chemical reducing agents, dimethylborane, hydrazine sulfate, sodium hypophosphite, citric or tartaric acid salts are most often used ${ }^{3}$. In this case, the surface of the dielectrics must be pre-activated. To obtain gold films, a contact method is also used, which consists of the reaction of substitution of the underlying metal for gold. It is obvious that in this case, it is necessary to pre-apply to the dielectric films of metals that can be replaced by gold. Usually, it is copper or nickel ${ }^{11}$.

It should be noted photochemical production of copper, silver and gold nanoparticles on the surface of polymer microspheres ${ }^{12}$. It is noted that the surfaces of polymer microspheres, acting as sorption centers of metal nanoparticles, provide the possibility of obtaining the latter in the form of stable dispersions. The disadvantage of the method is that the photochemical reaction with the formation of gold occurs only at a certain structure of the dielectric. Also in these works, the mechanism of photochemical reactions in the centers of sorption of metal nanoparticles is not disclosed. 


\section{EXPERIMENTAL PART}

It is known that most monovalent compounds of the copper subgroup disintegrate easily when heated slightly and under the action of light ${ }^{3}$. The photosensitivity of silver halides is used for photographic emulsions. It is also known that metal halides of the copper subgroup belong to the binary semiconductor. Therefore there is a connection between semiconductor properties and photosensitivity.

Therefore, to obtain metal films by photochemical method, it is necessary to create a layer of monovalent compounds of these metals on the dielectric surface. The use of aqueous suspensions of these compounds for this purpose is practically difficult since there are problems with the homogeneity of the films, their adhesion to the base. Therefore, the option of applying uniform films of soluble copper and gold compounds to the surface of materials, followed by their transfer to solid-phase monovalent compounds, is considered. Cotton gauze fabric (article AA010278), widely used for medical purposes, and synthetic polystyrene fabric were used for the study.

When conducting experiments on the application of gold films, tissue samples were immersed in a solution of $10 \mathrm{~g} / \mathrm{l} \mathrm{AuCl} \mathrm{Au}_{3}$ for 3 minutes.

In some experiments, a part of the sample surface was screened with a polymer spacer, which allowed distinguishing the boundary between the illuminated and unlit parts of the sample.

Then the sample was exposed to sunlight and kept until the film dries. After that, the spacer was removed and the sample was thoroughly washed with distilled water.

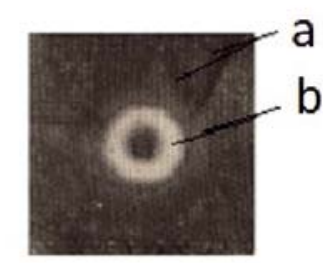

\section{Synthetic fabric}

Figure 1. Photos of tissue samples after photochemical gilding operation: $\mathrm{a}$ - the bright areas; $\mathrm{b}$ - spacer shielded areas

Similar operations were performed with samples of cotton fabric for 3 minutes lowered into a solution containing $10 \mathrm{~g} / \mathrm{l} \mathrm{AuCl}$. Then, by shaking, the excess solution of chlorine gold was removed. After that, the sample was illuminated with rays of sunlight. In this case, individual sections were screened with an opaque spacer made of a polymeric material.

Upon complete drying, a film of dark color was formed on the surface of the sample, characteristic of elemental gold obtained from salt solutions with the help of various reducing agents. Moreover, the film was formed only on the illuminated areas; the areas that were screened by a polymer spacer remained unchanged (Fig. 1).

Determination of thickness of films by means of "threads-witnesses" by the technique stated in work ${ }^{3}$.

The study of the composition of the film on various samples was carried out on a raster electron microscope ISM-6490-LV.
Figure 2 shows the border areas of the fabric, illuminated by the sun and obscured by an opaque spacer. At the same time, the darkened areas retained the dark color characteristic of the original fabric, and the illuminated areas acquired light tones characteristic of metals.

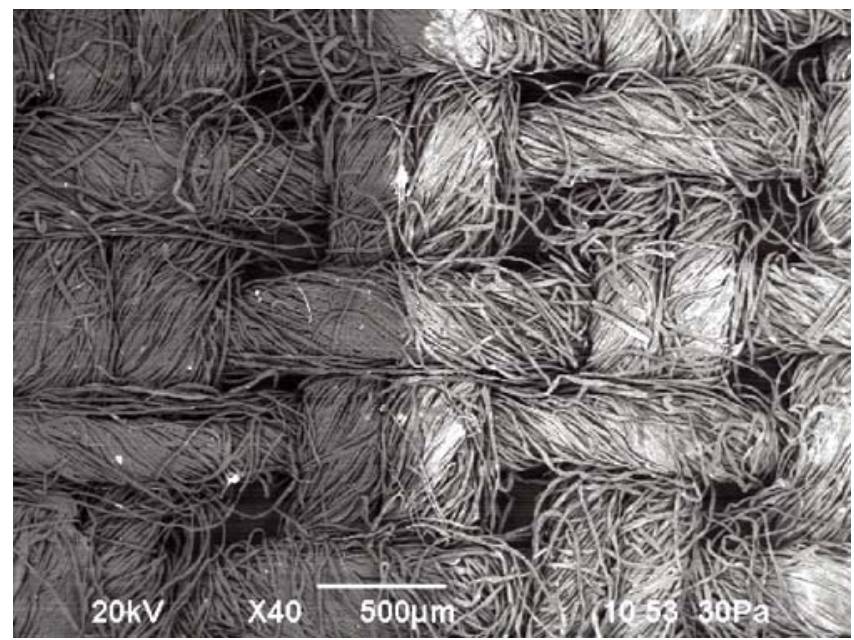

Figure 2. The boundary between the illuminated (right) and dark (left) areas of cotton fabric

The results of the analysis of the elemental composition of the surface layers of cotton fabric show the following. On the areas of fabric darkened by an opaque spacer (Fig. 2) color tissue, not changes, only on individual tracts are observed small the bright point. Elemental analysis shows that in addition to the elements characteristic of the original tissue (carbon, oxygen, silicon, calcium), a small amount of gold and chlorine is added. This indicates that the main part of the water-soluble layer of chlorine gold in these areas, as a result of the operation remains unchanged, and is removed by washing with water.

In the illuminated areas, a layer of elemental gold is formed as a result of photochemical reactions. At the same time, if consider that the surface layer contains 0.02 atomic percent of chlorine, which binds the same amount of atomic percent of gold in insoluble AuCI, and the total gold content is 0.60 atomic percent, more than $97 \%$ of the gold on the surface is in the form of metal.

When studying the structure (Fig. 3) of films consisting of metals of the copper subgroup, it was found that in all

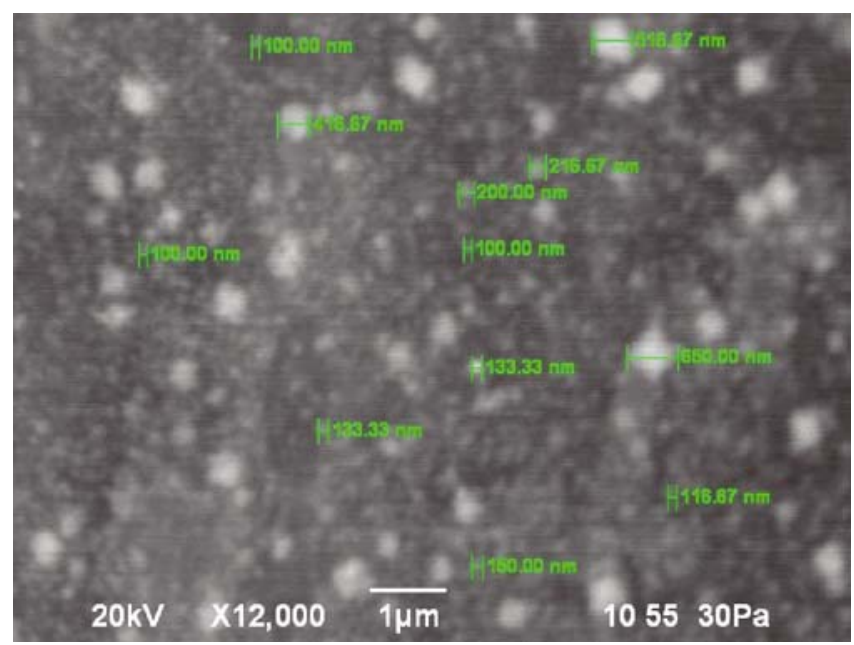

Figure 3. Structure of films of copper subgroup metals obtained by the photochemical method 
Table 1. Elemental composition of surface layers of cotton fabric

\begin{tabular}{|c|c|c|c|c|}
\hline \multirow{2}{*}{ Element } & \multicolumn{2}{|c|}{ Composition of illuminated areas, \% } & \multicolumn{2}{c|}{ Composition of the dark areas, \% } \\
\cline { 2 - 5 } & mass & atomic & mass & atomic \\
\hline $\mathrm{C}$ & 45.88 & 57.12 & 49.29 & 56.90 \\
\hline $\mathrm{O}$ & 44.73 & 41.70 & 48.95 & 42.50 \\
\hline $\mathrm{Si}$ & 0.95 & 0.50 & 0.84 & 0.41 \\
\hline $\mathrm{Cl}$ & 0.04 & 0.02 & 0.09 & 0.04 \\
\hline $\mathrm{Ca}$ & 0.09 & 0.03 & 0.19 & 0.06 \\
\hline $\mathrm{Au}$ & 7.87 & 0.60 & 0.64 & 0.04 \\
\hline
\end{tabular}

cases they are formed in the form of spherical particles, the average diameter of which is from several tens to several hundred nanometers.

Probably, depending on the intensity of the sun's rays, a certain number of quanta of light is absorbed by the system and drives charged particles: electrons or vacancies. The excess energy obtained by these particles allows you to go some distance and spend their oxidative or reducing process. At the same time, it is more energetically advantageous for electrons to move through already formed metal structures, giving them a spherical shape. Since the growth of the film occurs in different directions, including in areas where light does not get the thickness of the film can reach several micrometers.

\section{CONCLUSION}

In general, the thickness of the resulting films depends on several factors: the intensity of light rays, the structure of the fabric surface, the concentration of metal ions, the degree of reduction, the drying temperature, the presence of impurities. It is very difficult to take into account all these factors. But the main factor will be the concentration of metal ions. Thus, it was found that with an increase in $\mathrm{AuCl}_{3}$ concentration from $1 \mathrm{~g} / \mathrm{l}$ to $100 \mathrm{~g} / \mathrm{l}$, the total thickness of the coating varies from 0.09 microns to 1.5 microns.

\section{ACKNOWLEDGMENTS}

"This research is funded by the Science Committee of the Ministry of Education and Science of the Republic of Kazakhstan (Grant No. AP08956891)”.

\section{LITERATURE CITED}

1. Igal, K., Romina, A. \& Jorge, E. (2019). Antifungal activity of cotton fabrics finished modified silica-silver-carbon based hybrid nanoparticles. Textile Res. J. 5(89), 825-833. DOI: 10.1177/0040517518755792.

2. Szmuc, K., Kus-Liskiewicz, M., Szyller, Ł., Szmuc, D., Stompor, M., Zawlik, I., Ruman, T., Wołowiec, S., \& Cebulski, J. (2019). Silver nanoparticles deposited on calcium hydrogenphosphate -silver phosphate matrix; biological activity of the composite. Pol. J. Chem. Technol. 21(2), 6-13. DOI: 10.2478/ pjct-2019-0013.

3. Burkat, G.K. (2009). Jelektroosazhdenie dragocennyh metallov [in Russian: Electrodeposition of precious metals]. Saint-Petersburg, Russia: Politechnika.

4. Lansdown, A. (2002). Silver. Its antibacterial properties and mechanism of action. J. Wound Care, 11(4), 125-130. DOI: 10.12968/jowc.2002.11.4.26389.

5. Samsonov, N. \& Dudkin, N. (2014, June). Zolotaja traektorija - 2 [in Russian: The Golden path - 2]. Expert Sibir. 22, 10-17. Retrieved February 04, 2020, from World Wide Web: http://lib.ieie.nsc.ru/docs/2014/Samsonov_Dudkin_GoldExSib2014-22.pdf.

6. Stogni, A. \& Novitskyi, N. (2003, November). Poluchenie metodom ionno-luchevogo raspylenija kislorodom i opticheskie svojstva ul'tra tonkih plenok zolota [in Russian: Getting by using ion-beam sputtering with oxygen and optical properties of ultra thin films of gold]. J. Tech. Phys. 6(73), 86-89. Retrieved April 15, 2020, from Elibrary database on the World Wide Web: http://elibrary.lt/resursai/Uzsienio\%20leidiniai/ioffe/ztf/2003/06/ ztf_t73v06_15.pdf.

7. Tuleushev, A. (2003). Russian Federation Patent No. 2214476. Moscow, Russian Federation: Federal Service for Intellectual Property.

8. Kuchianov, A. (2013). Russian Federation Patent No. 2489230. Moscow, Russian Federation: Federal Service for Intellectual Property.

9. Shkundina, S. (2009, December). Novye processy i materialy $\mathrm{v}$ proizvodstve pechatnyh plat [in Russian: New processes and materials in printed circuit boards manufacturing]. Technologies in the electronics industry. 4, 16-20. Retrieved December 21, 2019, from World Wide Web: http://www.tech-e. ru/pdf/2009_04_16.pdf.

10. Satayev, M., Koshkarbaeva Sh. \& Tasboltaeva A. (2013, December). Metallization of the roducts of textile industry. Proceed. Higher Educ. Instit. Textile Ind. Technol. 2(348), 102-104. Retrieved December 21, 2019, from World Wide Web: https:// ttp.ivgpu.com/wp-content/uploads/2015/10/348.pdf.

11. Medvedev, A. \& Nabatov, U. (2010). Immersionnoe zolochenie pod pajku [in Russian: Immersion gold plating for soldering]. Technol. Electr. Ind. 2, 74-77. Retrieved December 21, 2019, from World Wide Web: https://www.tech-e. ru/2010_2_6.php

12. Isaeva, A., Boitsova, T. \& Gorbunova, V. (2007). Photochemical synthesis of gold nanoparticles in aqueous dispersions of carboxylated polystyrene. Russ. J. Gen. Chem. 5(77), 812-817. DOI: 10.1134/S1070363207050027. 